\title{
Políticas de InCLUSÃo E A REALIDAdE PROFISSIONAL: A EXPERIÊNCIA DE UMA GRADUANDA CEGA NO ESTÁGIO CURRICULAR SUPERVISIONADO
}

INCLUSION POLICIES AND THE PROFESSIONAL REALITY: THE EXPERIENCE OF A BLIND GRADUATE IN THE SUPERVISED CURRICULAR INTERNSHIP

Kalina Salaib Springer Doutora em Geografia pela Universidade Estadual de Campinas. Docente da Universidade Federal de Santa Catarina. Santa Catarina - SC - Brasil springer.kalina@gmail.com

Sabrina Mangrich de Assunção Graduada em Geografia pela Universidade Federal de Santa Catarina. Santa Catarina - SC - Brasil sabrina.m.a@hotmail.com

Yanna D'Angelis de Carvalho Gonçalves Mestranda em Geografia pela Universidade Federal de Santa Catarina. Santa Catarina

- SC - Brasil yannaufsc@hotmail.com

Resumo: Neste texto, abordaremos aspectos relacionados às políticas de inclusão de pessoas com deficiência e seus desdobramentos no que tange à inserção deste indivíduo no mercado de trabalho. Para tanto, relataremos a experiência de uma graduanda cega, em seu estágio 
curricular obrigatório no curso de Licenciatura Plena da Universidade Federal de Santa Catarina. Percebeu-se, que, mesmo com toda a política de inclusão já existente, a escola e os alunos, não estão preparados para receber um docente cego ${ }^{1}$. A inclusão envolve a adequação das escolas e da sociedade para receber essas pessoas, de modo a promover a cidadania, como pessoas possuidoras dos mesmos direitos, dentre eles o direito de estudar e trabalhar.

Palavras-chave: Inclusão. Política educacional. Realidade profissional.

Abstract: In this text, we will discuss aspects related to the policies of inclusion of people with disabilities and their consequences regarding the insertion of this individual in the labor market. To do so, we will report on the experience of a blind undergraduate student1, in her compulsory curricular internship in the Full Degree course of the Federal University of Santa Catarina. It has been realized that, even with all the existing inclusion policies, the school and the students are not prepared to receive a blind teacher. This involves the adequacy of schools and society to receive these people, in order to promote citizenship, as persons having the same rights, among them the right to study and work.

key-words: Inclusion. Educational policy. Professional reality.

\section{Introdução}

questão da inclusão de pessoas com deficiência $(\mathrm{PCD})^{2}$ ainda é muito
incipiente no Brasil. A estrutura de nossa sociedade, desde os seus primórdios, contribuiu para o processo de marginalização e exclusão social destas pessoas. Contudo, este pensar discriminatório, tem sido, combatido sobretudo por ações de educadores e de pais que, buscam por meio do conhecimento a alteração da visão social destas pessoas; sua inclusão na rede escolar; criação e acatamento à legislação vigente e ampliação de verbas para programas sociais.

É nesse contexto de lutas, que surge a Política de Inclusão de Pessoas com Deficiência no Brasil, das quais muitos já se beneficiaram. Partindo dessa premissa é objetivo deste artigo refletir se a política de inclusão proporciona uma efetiva inclusão daqueles por ela beneficiados. Assim, para além de um apanhado histórico acerca das políticas de inclusão, abordaremos facilidades e dificuldades encontradas no âmbito profissional. 
Tais reflexões objetivam trazer subsídios para compreender se, estas políticas promovem a inclusão, proporcionando as bases para, ao final do curso, estes profissionais ingressarem no mercado formal de trabalho. Por outro lado, é objetivo também, refletir se, o mercado de trabalho, está preparado para receber estes profissionais, promovendo uma efetiva inclusão e não somente a integração destas pessoas.

Estas reflexões tiveram como base a experiência docente realizada durante o estágio curricular supervisionado no curso de Licenciatura Plena da Universidade Federal de Santa Catarina. Apresentando-se como um estudo de caso, esta pesquisa realizou-se no Colégio de Aplicação (UFSC), local de realização do estágio em uma turma do ensino médio no ano de 2016.

\section{A política de inclusão no Brasil: breves considerações}

A Educação Especial no Brasil é marcada por diversas fases segundo afirma Sassaki (1997), sendo elas: exclusão, segregação institucional, integração e inclusão. Para o autor, na fase da exclusão as pessoas com deficiências eram ignoradas, rejeitadas, perseguidas e exploradas, não havendo nenhuma forma de atenção educacional.

Já, na fase da segregação institucional surgiu a ideia de deficientes na educação, tendo em vista, a política educacional brasileira. Com isso, iniciou-se a preocupação com o desenvolvimento educacional das pessoas cegas, surdas, deficientes mentais e deficientes físicos, através do atendimento educacional nas chamadas instituições especializadas.

Assim, nas décadas de 1950 e 1960 houve várias iniciativas na área da educação especial, refletindo num aumento considerável de serviços de ensino especial. Um exemplo desse processo foi a criação de instituições filantrópicas, como a fundação da 
GRADUANDA CEGA NO ESTÁGIO CURRICULAR SUPERVISIONADO

Associação de Pais e Amigos do Excepcional (APAE) em 1954. Mazzota (1996) relata que em 1957, o governo brasileiro iniciou campanhas, com a finalidade de atender a cada deficiência, de modo que, os surdos foram os primeiros a serem contemplados.

Apenas em 1961, a educação de excepcionais, como era denominada educação especial, teve um capítulo com os artigos 88 e 89 na LDB: "A educação de excepcionais, deve, no que for possível, enquadrar-se no sistema geral de educação, a fim de integrálos na comunidade" (Art. 88, LDB, n. $\left.{ }^{\circ} 4.024 / 61\right)^{3}$. Assim, as pessoas com deficiência passam a ter o direito de frequentar o ensino regular. Para Mazzota (1996) este foi um avanço, pois garantiu o direito à educação no ensino regular, sendo a primeira menção a este grupo nas políticas educacionais brasileiras.

Com a inserção destes alunos no ensino regular, surge a fase da integração. De acordo com Sassaki (1997) esta fase inicia-se com expressivo aumento das classes especiais nas escolas de ensino regular, porém em espaços separados dos demais. Essas salas se baseavam na compreensão de que estando em salas à parte, separados dos alunos sem deficiência, os ditos "excepcionais" não atrapalhavam o ensino dos demais. Nesse mesmo sentido, Blanco (2002, p.08), menciona que “[...] assim, quando se começa uma experiência de integração, é reproduzido, no interior da escola, o mesmo enfoque da escola especial".

Colocando assim, o termo 'integração’ se refere a inserir no convívio social a pessoa com deficiência que já tenha sido preparada, capacitada, instruída e que esteja adaptada para viver em sociedade. Assim, esta 'integração' ocorreu de forma relativa, visto que os alunos passavam por um treinamento, uma adaptação para se adequar tanto na educação regular, quanto na vida social. Destaca também, que a escola permaneceu sem alterações, dividida entre a educação regular e a especial, sendo o enfoque nas patologias. Como complementa Glat e Nogueira (2002): 
Denominamos integração o modelo que começou a serem implantados no Brasil desde o final da década de 70, os alunos com necessidades educacionais especiais, geralmente oriundos do ensino especial, são inseridos na sala regular na medida em que demonstrem condições para acompanhar a turma, recebendo atendimento especializado paralelo, em horário alternativo, individualmente ou em salas de recursos. (GLAT; NOGUEIRA, 2002, p. 12).

Em 1972, foi constituído o grupo tarefa de educação especial, pelo ministério da Educação e cultura. Este grupo criou a primeira proposta de políticas e ações para educação especial no país. Para gerenciar, promover melhorias e expansão na educação especial, foi criado o Centro Nacional de Educação Especial (CENESP), órgão central vinculado ao MEC (MAZZOTA, 1996). Em 1986 este órgão passa a se chamar Secretaria de Educação Especial (SESPE), mantendo basicamente as mesmas atribuições. Ao fim de 1992, a SEESP passa a ser vinculada ao Ministério de Educação e Desporto.

Mazzota (1996) destaca que a partir do fim da década de 1980 e início dos anos 1990, as pessoas com deficiência começaram a se organizar em movimentos, promovendo encontros, palestras, simpósios, de forma a contribuir para ampliação da participação efetiva deste grupo, e conseguem levar suas necessidades e demandas às diversas esferas governamentais.

Mazzota (1996) destaca também, que a capacidade de pressão destes grupos organizados, tiveram reflexos significativos na elaboração das legislações em vários aspectos da vida social, tendo destaque as conquistas concretizadas na constituição federal de 1988 e nas constituições estaduais, como exemplo a seguridade social, reabilitação, trabalho e transporte.

A Constituição Federal de 1988, diz que o aluno com deficiência deveria estar na escola, e se possível sua educação deveria acontecer em classe regular de ensino, junto às demais crianças sem deficiência. Então no seu art. 205, aborda que deve haver 
GRADUANDA CEGA NO ESTÁGIO CURRICULAR SUPERVISIONADO

a educação para todos como direito subjetivo para que as pessoas possam conviver e interagir normalmente, atendendo a diversidade humana. Ainda aponta no seu artigo 206 e 208, respectivamente, o acesso e permanência na escola e afirma que deve haver o Atendimento Educacional Especializado (AEE) às pessoas com deficiência, preferencialmente, na rede regular de ensino.

Neste contexto, em 1999 publica-se o Decreto 3.298 que regulamenta a Lei no 7.853, de 24 de outubro de 1989 e dispõe sobre a Política Nacional para a Integração da Pessoa Portadora de Deficiência. A lei estabelece que, a educação especial está integrada ao ensino regular como modalidade que perpassa todos os níveis de ensino, sendo obrigatória e gratuita em estabelecimentos públicos de ensino.

Ainda na década de 1990 a Conferência Mundial sobre Educação Especial em Salamanca, redigiu um documento, estabelecendo diretrizes básicas, que subsidiaram a formulação e reforma nos sistemas educacionais para que estivessem que acordo com movimento de inclusão social. Fica estabelecido que, as escolas de Ensino regular devem educar os alunos, enfrentando todas as situações que possam gerar exclusão escolar: crianças com deficiências, que vivem nas ruas, que trabalham, superdotadas, em desvantagem social, ou ainda que apresentam diferenças linguísticas, étnicas e culturais.

Neste contexto, em 2001 o Congresso Nacional aprovou o texto da Convenção Interamericana para a Eliminação de Todas as Formas de Discriminação contra as Pessoas Portadoras de Deficiência por meio do Decreto Legislativo no 198, de 13 de junho. O texto ratifica os direitos e liberdades fundamentais para as pessoas com deficiência, definindo discriminação como toda atitude de diferenciação. E, a partir dele, surgem várias leis, decretos, diretrizes e normas que tratam de questões pertinentes a educação especial, promovem o ensino inclusivo e dispõe sobre os direitos das pessoas com PCDs ${ }^{4}$.

Cadernos de Pós-graduação, São Paulo, v. 17, n. 2, p. 223-238, jul./dez. 2018. 
Assim, toda a criança tem direito fundamental à educação, e deve ser dada a oportunidade de atingir e manter o nível adequado de aprendizagem; toda criança possui características, interesses, habilidades e necessidades de aprendizagem que são únicas. Com isso, os sistemas educacionais deveriam ser implementados no sentido de se levar em conta a vasta diversidade de tais características e necessidades.

Logo, a Declaração de Salamanca abriu caminho para um avanço significativo ao destacar a valorização da individualidade de cada educando independente de ser deficiente sensorial ou não. E, a escola, passa a ser pensada para que, consiga atender a todos em suas diferenças ou dificuldades individuais. Para Mazzotta \& Souza (2000, p.98), tal Declaração "tem sido o referencial básico para os mais recentes debates sobre Educação para Todos com a denominação de Educação Inclusiva”.

Assim, na fase da 'inclusão' segundo Mantoan (1997) e Sassaki (1997), a sociedade identifica a necessidade de adaptação entre as pessoas com deficiência e a sociedade e vice-versa. De acordo com Sassaki (1997) a integração significa inserção da pessoa deficiente preparada para conviver em sociedade e a inclusão significa modificação da sociedade como pré-requisito para que a pessoa com deficiência busque seu desenvolvimento e exerça sua cidadania. Quando nos referimos ao termo ‘inclusão’ significa conscientização, modificação, adaptação e preparação de uma sociedade para incluir as diversidades.

Conforme Glat e Nogueira (2002, p. 12) na inclusão, esses alunos, independente do tipo ou grau de comprometimento, devem ser matriculados diretamente no ensino regular, cabendo à escola se adaptar para atender às suas necessidades na classe regular. Assim Blanco (2002, p.31), coloca que "a instituição tem que incluir, sustentar, acompanhar, apoiar, enriquecer e oferecer tudo o que esta pessoa necessita em sua singularidade para ter êxito no objetivo de integrar". 


\section{O Estágio Supervisionado: Um Relato de Experiência}

O estágio supervisionado é o momento em que o graduando tem contato de forma direta com a escola, observa, interage, identifica problemas, aspectos positivos, e inicia a prática docente. Ele é indispensável por possibilitar um olhar sobre a complexa realidade da escola, existente no processo de ensino e de aprendizagem, bem como exercício de reflexão sobre esta realidade e, o contato e familiaridade com o cotidiano do espaço escolar. Assim, o estágio proporciona a oportunidade de vivência e aprendizagem da docência (MARTINS, 2014).

Esta experiência é uma oportunidade em que os licenciandos, têm para atuarem em Sala de aula e refletir sobre este ambiente, é também, um momento de aproximação com a realidade concreta da sala de aula, momento de incertezas, de aprendizagem profissional, crescimento tanto pessoal como coletivo, e outros inúmeros aspectos que permeiam esta etapa da formação, sendo o eixo central da formação acadêmica do licenciando (SANTOS, 2013; MARTINS, 2014).

Pimenta e Lima (2005) destacam que nos cursos em geral, o estágio sempre foi identificado como a parte prática em contrapartida a parte teórica vista nas disciplinas dos cursos, no entanto, a escola não deve ser percebida apenas como o local da prática e a universidade como da teoria. Teoria e prática se interpenetram ao se complementarem e interagem constantemente, portanto, não estão dissociados, visto que não existe prática sem teoria e vice-versa. Na docência são necessárias habilidades e competências concretas, por meio da teoria e da prática que estão articuladas ao ensino de forma a se relacionar e contextualizar ao momento atual, do ensino e do aprendizado (SANTOS, 2013).

Pimenta e Lima (2005) trazem que a teoria tem o papel de oferecer aos 
professores perspectivas de análise, que possibilita compreenderem os inúmeros contextos sociais, históricos, organizacionais, culturais e de si mesma como profissionais, onde ocorrem suas atividades docentes, para neles intervir e poder transformá-los.

Contreras (2002) destaca que a prática vai além de se dominar o conhecimento profissional ao se deparar com situações inesperadas, ela proporciona a construção de um sistema de valoração ao se tomar decisões e se ter a percepção do alcance social de suas ações. Martins (2014) lembra que a prática deve ser reflexiva, investigativa e problematizadora para que o futuro professor seja autônomo e responsável pelo seu processo de ensino e aprendizagem, tomada de decisões sobre sua prática e sua realidade na escola.

$\mathrm{Na}$ UFSC o estágio supervisionado do curso de licenciatura em Geografia ocorre em dois momentos, no decorrer de um ano letivo. No primeiro semestre, as duplas observam as aulas, o contexto escolar e planejam as aulas da regência para o segundo semestre assumirem a turma.

As observações ocorreram em duas turmas distintas. Em ambas turmas, os alunos agiram de forma natural à entrada da estagiária cega na sala. O Colégio de Aplicação têm políticas de inclusão de PCDs propiciando o convívio e consequente naturalização da deficiência, além disso, os alunos foram avisados previamente da condição da estagiária.

Durante as aulas observadas, a dupla de estágio auxiliava no entendimento geral ao descrever as situações que estavam ocorrendo, o que era passado no quadro, imagens projetadas e folhas de xerox entregues. As estagiárias sentavam-se no fundo da sala, circulando para auxiliar e conhecer melhor a turma durante os momentos de atividades.

Um detalhe que chamou atenção e despertava a curiosidade de alguns alunos era o fato da estagiária cega, escrever no tablet com a tela desligada e se utilizar um 
GRADUANDA CEGA NO ESTÁGIO CURRICULAR SUPERVISIONADO

teclado que utiliza pontos em braile, Os alunos, curiosos, mas envergonhados, perguntavam a estagiária vidente, que por sua vez pedia para a estagiária cega explicar.

Em paralelo, foi realizado o primeiro contato com a prática docente. A primeira regência ocorreu no fim de maio e abordou conteúdos da cartografia. Com enfoque para os elementos que compõe o mapa e a atividade foi desenhar a planta da sala, utilizando pés como unidade de medida. Já nessa primeira experiência, notou-se a falta de confiança dos alunos com relação à estagiária cega. Todos os questionamentos dirigiam-se primeiramente à estagiária vidente. Faltava aos alunos confiança e segurança com relação ao conhecimento e à capacidade da estagiária cega desenvolver as atividades docentes.

No segundo semestre as regências ocorrem de forma a integrar as aulas ministradas pelos estagiários ao conteúdo anual a ser ensinado em determinado nível escolar. Antes de iniciar as regências, observou-se que os alunos estavam ansiosos para que as estagiárias começassem. Assim, foi comentado sobre quais assuntos seriam abordados e as atividades a serem realizadas.

Baseando-se nas dificuldades identificadas pela estagiária cega na primeira regência, pediu-se aos alunos que adotassem procedimentos simples como, por exemplo: os alunos chamar pelo nome e não apenas levantar a mão para tirar dúvidas ou fazer algum comentário, não deixar mochila no chão, evitar deixar carteiras bagunçadas na hora das atividades, principalmente quando for à estagiária cega que estiver ministrando aulas. Esses procedimentos manteria a organização da sala, facilitando a locomoção da estagiária cega.

Nas primeiras aulas a ansiedade, insegurança, atrapalhou um pouco na explicação dos conteúdos. As aulas foram em dupla, utilizando-se vários slides com fotos, mapas e gráficos. Neste caso, a pessoa cega tem que ter clareza e segurança com relação às imagens a serem apresentadas, ou ter um mapa e esquemas táteis para auxiliar 
na explicação. Isso é necessário, pois, nem sempre os alunos irão conseguir descrever as imagens, como ocorreu algumas vezes em que foi pedido que eles descrevessem as imagens para participarem e perceber o que podiam compreender da mesma.

Para exemplificar, durante uma aula cujo tema era vegetação do estado de Santa Catarina, foi pedido que descrevessem as imagens que apareciam no slide bem como os mapas de vegetação e em resposta os alunos apenas diziam que era um mapa, ao serem instigado mais, para falar elementos de detalhe do mapa para, a partir disso, a graduanda cega conduzir a aula.

Em uma das aulas, a atividade era a elaboração de mapas táteis e texto auxiliar sobre os conteúdos clima, relevo, vegetação, hidrografia, geologia e geomorfologia de Santa Catarina. A sala foi dividida em duplas, onde cada dupla ficou responsável por um tema, tendo que fazer um resumo a partir de um texto base e um mapa tátil ${ }^{5}$.

Durante a execução a turma ficou agitada, e as estagiárias tiveram dificuldade em explicar e conduzir a atividade. Os alunos falavam ao mesmo tempo e as estagiárias tentavam se sobrepor as vozes a dos alunos. Essa falta de organização dos alunos, dificultava que a estagiária cega pudesse ouvir as indagações.

Outro ponto a ser mencionado é que a estagiária cega teve maior dificuldade em perceber a compreensão ou não dos assuntos pelos alunos. Diferentemente do professor vidente, durante a explicação, é importante que os alunos interajam, falem, deem exemplos. Já que não é possível ver a expressão da turma, isso é importante para que a pessoa cega possa ter o retorno de que eles estão compreendendo. Se ficam em silêncio, existe dúvida se compreenderam ou não.

Cabe ainda, relatar a experiência de um debate, em que, a turma foi dividida em dois grupos, "contra" e "a favor" da implantação de uma agroindústria, tendo que pesquisar e trazer argumentos. Para organizar a atividade, as carteiras foram dispostas em círculo, facilitando o deslocamento da estagiária cega. Além disso, pediu-se para que 
GRADUANDA CEGA NO ESTÁGIO CURRICULAR SUPERVISIONADO

os alunos, se identificassem no início de cada fala, estratégia importante para que a estagiária cega pudesse relacionar a voz ao aluno. Não se percebeu dificuldade e o debate prosseguiu com naturalidade, sendo que os próprios alunos lembravam uns aos outros de falar o nome.

De modo geral, as dificuldades encontradas pelas estagiárias eram as mesmas, contudo algumas potencializam-se na estagiária cega. Ainda sim, essas dificuldades e obstáculos não interferiram no andamento do estágio, mas exigiram da estagiária cega grande esforço, paciência e capacidade de adaptação.

As conversas paralelas e perguntas simultâneas dificultavam a explicação de ambas, e fazia com que a estagiária cega, por vezes, se perdesse no 'falatório' generalizado. A desorganização da turma com mochilas e bolsas espalhados no chão e carteiras fora do lugar dificultava o atendimento aos alunos de modo a inibir seu deslocamento com medo de cair ou tropeçar. A falta de interesse e apatia dos alunos que também se dispersavam facilmente dificultavam a regência da estagiária cega, que, precisava de uma interação oral (porém organizada) da turma para conduzir certos conteúdos.

Observou-se ainda dificuldade dos alunos em reportar suas dúvidas a estagiária cega, de modo que, inicialmente, sempre, direcionavam-se à estagiária vidente. Percebeu-se que isso acontecia devido a dois fatores: à falta de confiança no conhecimento da estagiária cega e à certa "vergonha" ou receio de fazê-lo. Com o decorrer do estágio e das aulas, esse problema foi rapidamente solucionado.

No mais, não foi observado diferenças significativa de comportamento dos alunos entre as duas estagiárias (cega e vidente). Brincadeiras próprias da idade, aconteciam independente de quem estivesse à frente da aula (estagiária vidente, cega ou o professor regente). A turma assumiu diante das estagiárias, postura similar de desorganização, desinteresse, apatia ou de animação, comprometimento e empenho nas 
atividades.

\section{Considerações Finais}

A regência durante o estágio supervisionado é pouco tempo para realizar uma análise mais profunda das reais facilidades e dificuldades de um docente cego no exercício da profissão. No entanto, a experiência aqui relatada confirma que, a efetiva inclusão das pessoas com deficiência, vai muito além de sua integração á sociedade. Este é o primeiro passo, representando o início de um processo longo que deve envolver toda a todos. No que tange à formação profissional, ficou claro que a universidade cumpriu seu papel, de modo a, propiciar à aluna cega, todo conhecimento teórico necessário ao exercício profissional. A estagiária cega, está pronta para seguir sua profissão de forma autônoma.

Contudo, percebeu também, que, mesmo com toda a política de inclusão já existente, a escola e os alunos, não estão preparados para receber um docente cego. Esta, envolve a adequação das escolas e da sociedade para receber essas pessoas, de modo a promover a cidadania, como pessoas possuidoras dos mesmos direitos, dentre eles o direito de estudar e trabalhar.

As escolas de modo geral, não possuem infraestrutura necessária para receber alunos e tão pouco profissionais com deficiências. Mesmo o Colégio Aplicação sendo referência no trato aos PCDs, não possui infraestrutura arquitetônica que permita o livre deslocamento (incluindo as salas de aula superlotadas), infraestrutura eletrônica quanto a programas de acessibilidade nos computadores ou materiais didáticos adaptados disponíveis. A estagiária cega apresentou dificuldades na elaboração de aulas e atividades principalmente pela falta de material de base adaptado.

Evidenciou-se também a necessidade de alguém para auxiliar e acompanhar o 
GRADUANDA CEGA NO ESTÁGIO CURRICULAR SUPERVISIONADO

professor cego em determinados momentos como na correção das atividades e avaliações (escritas) ou ainda na utilização do quadro branco ou outros recursos. As políticas de inclusão de alunos com deficiência, não prevê esse apoio e não há legislação que regulamente ou que viabilize uma efetiva inclusão de profissionais, professores cegos, no ambiente escolar.

O que torna a pessoa deficiente, não é a deficiência, mas o ambiente que não está preparado para incluir essas pessoas. Acreditamos que, as escolas que se propõem a serem inclusivas, se constituem os meios mais eficazes de combater atitudes discriminatórias criando-se comunidades acolhedoras. Consequentemente, estes espaços, auxiliam na construção uma sociedade inclusiva garantindo direitos e educação para todos.

\section{Referências}

BLANCO, Maria Rosa. Implicações educativas do aprendizado na diversidade. Gestão em Rede 38, Edição Temática - Como realizar o ensino inclusivo, 2002, pp. 06-11.

BRASIL. Constituição Federal Constituição da República Federativa do Brasil: promulgada em 5 de outubro de 1988. Disponível em:

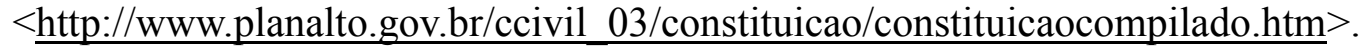

BRASIL. LDB (1996).Lei $N^{\circ}$ 9394, de 20 de dezembro de 1996. Estabelece as diretrizes e bases da educação nacional. Disponível em:

$<\underline{\text { http://www2.camara.leg.br/legin/fed/lei/1996/lei-9394-20-dezembro-1996- }}$ 362578-norma-pl.html>

CONTRERAS, J. Autonomia de professores. São Paulo, Cortez, 2002.

GLAT, Rosana; NOGUEIRA Mario Lucio de Lima. Políticas Educacionais e a formação de professores para a educação Inclusiva no Brasil. Revista Integração, 
Brasília, DF, ano 14, v. 24, p. 22-27, 2002.

MANTOAN, Maria Teresa Eglér Mantoan. Ser ou estar, eis a questão: compreendendo o déficit intelectual. Rio de Janeiro: WVA Editora, 1997.

MARTINS, Rosa. E. M. W.- Um diálogo acerca das experiências dos estagiários no contexto do estágio de docência em geografia. In: GIOIDAUI, Ana Cláudia (Org.). Aprender geografia: a vivência como metodologia. Porto Alegre: Evangraf, 2014.

MAZZOTTA, Marcos José Silveira. Educação especial no brasil: história e políticas públicas. São Paulo: Cortez, 1996.

MAZZOTA, Marcos José Silveira; SOUZA. Sandra, Zákia. Inclusão escolar e educação especial: considerações sobre a política educacional brasileira. Revista Estilos da Clínica, vol.5, n. 9, São Paulo: IPUSP, 2000, pp. 96-108.

PIMENTA, Selma. Garrido., LIMA, M. S. L. Estágio e docência: diferentes concepções. Revista Poíesis Pedagógicas, v. 3, n. 34, p.05-24, 2005.

SANTOS, M. F. P. A relação teoria-prática no estágio supervisionado em Geografia. In: CASTROGIOVANNI, Antônio Carlos Castrogiovanni; TONINI, Ivaine Maria; KAERCHER, Nestor André (Org.). A relação teoria-prática no estágio supervisionado em Geografia. Porto Alegre: Imprensa Livre, 2013, p. 253272.

SASSAKI, Romeu, K. Inclusão: construindo uma sociedade para todos. Rio de Janeiro: WVA, 1997. 
$1 \quad$ O termo cego(a) foi escolhido pela aluna cega para se autodefinir-se. E, tem como objetivo evitar conotações pejorativas que o termo portador de deficiência visual ou deficiente visual possa acarretar. Apesar de a literatura oficial trazer PCDs e este termo ser empregado ao longo do artigo.

2 PCD - Pessoa Com Deficiência - Termo utilizado nos documentos oficiais do governo Brasileiro, para designar as pessoas com algum tipo de deficiência, seja física ou mental.

3 Em vigência atualmente, a LDB sofreu alterações conceituais pela Lei n. ${ }^{\circ} 12796$ de 2013 e possui um capítulo dedicado à educação especial. Este capítulo, no artigo 58, conceitua educação especial, e apresenta a expressão "pessoa com deficiência" em substituição à "portador de deficiência". Já, o art. 59 determina aos sistemas de ensino a obrigatoriedade em garantir medidas que facilitem o aprendizado do estudante por meio de métodos, materiais, currículos e organização que atenda as necessidades do educando.

$4 \quad$ Entre as quais mencionamos: reconhecimento da Libras como língua oficial e sua obrigatoriedade nos cursos de formação docente. Em 2011 o Decreto n7612/2011 institui o Plano Nacional dos Direitos da Pessoa com Deficiência. A lei tem a finalidade de promover, por meio da integração e articulação de políticas, programas e ações, o exercício pleno e equitativo dos direitos das pessoas com deficiência, nos termos da Convenção Internacional sobre os Direitos das Pessoas com Deficiência, garantindo, entre outros, um sistema educacional inclusivo. Em 2012 a Política Nacional de Proteção dos Direitos da Pessoa com Transtorno do espectro autista foi criada pela Lei $n^{\circ} 12.764 / 2012$. Onde vale destacar a vetação de se recusar a matrícula a pessoas com qualquer tipo de deficiência além de estabelecer punições a quem praticar esse ato discriminatório. Aprovação em 2015 da lei № 13.146 do Estatuto da pessoa com deficiência.

5 Mapa base disponibilizado pelo Laboratório de Cartografia Tátil e Escolar (LabTate - UFSC). http://www.labtate.ufsc.br/

recebido em 10 ago. 2017 / aprovado em 14 set. 2018

Para referenciar este texto:

SPRINGER, K. S.; ASSUNÇÃO, S. M.; GONÇALVES, Y. D'A. C. Políticas de Inclusão e a realidade profissional: a experiência de uma graduanda cega no Estágio Curricular

Supervisionado. Cadernos de Pós-graduação, São Paulo, v. 17, n.2, p. 223-238, jul./dez. 2018. Disponível em: <https://doi.org/10.5585/cpg.v17n2.7667> 